\title{
Travel from the United Kingdom to the United States by a Symptomatic Patient Infected with the SARS-CoV-2 B.1.1.7 Variant - Texas, January 2021
}

\begin{abstract}
Moriam Ojelade, $\mathrm{PhD}^{1}$; Annette Rodriguez, $\mathrm{MPH}^{1}$; Dante Gonzalez, $\mathrm{PhD}^{1}$; Denzel Otokunrin, $\mathrm{MPH}^{1}$; Srikanth Ramachandruni, $\mathrm{MD}^{1}$; Elizabeth Cuevas, $\mathrm{PhD}^{2}$; Kelly Moon, $\mathrm{MSc}^{2}$; Carla Gutiérrez Tyler, $\mathrm{MPH}^{2}$; Melissa Freeland, $\mathrm{MPH}^{2}$; Mark Anderson, $\mathrm{MD}^{3}$; Kambria Haire, $\mathrm{PhD}^{3}$; Yuridia Orozco, $\mathrm{MS}^{4}$; Fija Scipio, $\mathrm{MS}^{3}$; Yuri Springer, $\mathrm{PhD}^{3}$; Emilie Prot, DO²; Jennifer A. Shuford, $\mathrm{MD}^{2}$
\end{abstract}

On March 3, 2021, this report was posted as an MMWR Early Release on the MMWR website (https://www.cdc.gov/mmwr).

In December 2020, the B.1.1.7 genetic variant of SARS-CoV-2, the virus that causes COVID-19, was first reported after emergence and rapid circulation in the United Kingdom (1). Evidence suggests that the B.1.1.7 variant is more efficiently transmitted than are other SARS-CoV-2 variants, and widespread circulation could thereby increase SARS-CoV-2 infection and hospitalization rates $(1,2)$. The first reported SARS-CoV-2 B.1.1.7 variant case in the United States was confirmed by sequencing in Colorado on December 29, 2020.* This report describes a person who traveled from the United Kingdom to the United States after experiencing COVID-19-compatible symptoms ${ }^{\dagger}$ and was eventually confirmed to be infected with the B.1.1.7 variant.

On January 10, 2021, CDC notified the Texas Department of State Health Services (DSHS) of a SARS-CoV-2 B.1.1.7 variant case; Corpus Christi-Nueces County Public Health District staff members conducted a case investigation on January $10-11$. The patient, aged 61 years, had visited family in the United Kingdom during November 13-December 30, 2020, and reported having been exposed to a relative experiencing COVID-19-compatible symptoms (cough, runny nose, and headache) on December 24. Another relative at the same gathering received a positive COVID-19 test result in the United Kingdom on January 10. The patient received a negative SARS-CoV-2 antigen test result on December 28 in preparation for travel back to the United States but experienced symptoms on December 29 and reported taking acetaminophen on December 30. On December 30, the patient disclosed a runny nose during the pretravel interview but was cleared to fly from London to Dallas, Texas the same day. Upon arrival in the United States on December 31, the patient stayed overnight in a hotel and then drove home (approximately 8 hours). On the way home, the patient stopped five times, including twice

\footnotetext{
*https://covid19.colorado.gov/press-release/cdphe-confirms-two-additionalcases-and-one-possible-case-of-the-b117-variant

$\dagger$ Patient initially experienced runny nose and headache before departure and later experienced loss of taste and smell, severe headache, chills, and a dry cough after return to the United States, which are symptoms compatible with COVID-19. https://www.cdc.gov/coronavirus/2019-ncov/symptoms-testing/ symptoms.html; https://www.cdc.gov/flu/symptoms/flu-vs-covid19.htm
}

for food, twice for gas, and once at a grocery store. Throughout the international and domestic travel period, the patient reported trying to maintain physical distance from others and wearing a cloth face mask, except while eating or drinking. The patient began self-quarantine upon returning home, which was broken twice for a medical and testing appointment. Additional symptoms, including loss of taste and smell, severe headache, chills, and a dry cough, began on January 1 . On January 2, the patient sought confirmation of SARS-CoV-2 infection by real-time reverse transcription-polymerase chain reaction (RT-PCR) testing and received a positive test result on January 4, at which point the patient began a 10-day isolation. The RT-PCR exhibited S-gene target failure, a diagnostic test result suggestive of the B.1.1.7 variant (2). This finding was confirmed by sequencing at a commercial laboratory affiliated with CDC's national strain surveillance system. ${ }^{\$}$

As part of the contact investigation, Texas DSHS shared the patient's flight information with the CDC El Paso Quarantine Station on January 11. Because 12 days had passed since the flight, CDC did not initiate an aircraft contact investigation; however, CDC later provided an informational notification to the states because of the variant case. The patient's single asymptomatic pediatric household contact was not tested but quarantined concurrently with the patient. No secondary cases with epidemiologic links to the patient have been identified to date.

This case demonstrates how a variant of concern, in this case B.1.1.7, might be translocated between communities through travel. At the time of this person's travel, CDC had an order in place requiring proof of a negative SARS-CoV-2 test $\leq 3$ days before departure, or documentation of recovery from COVID-19, for all air passengers boarding a flight to the United States from the United Kingdom (3). Subsequently, on January 12, CDC issued an order expanding this requirement to all international air passengers arriving in the United States, effective January 26, 2021 (4). Because of the lower sensitivity of some SARS-CoV-2 antigen tests $(5,6)$, the potential for false-negative results when nucleic acid amplification tests (such as RT-PCR) are administered shortly after infection with

\footnotetext{
$\$$ Response/Pages/Sequence-Based-Surveillance-Submission.aspx
} 
SARS-CoV-2 (7), and the subsequent potential for exposing others after a test is administered, predeparture testing should be considered one component of a comprehensive travel risk management strategy. Properly timed testing, both before and after travel, together with self-monitoring for symptoms, a period of self-quarantine after travel, use of a well-fitting mask, hand hygiene, and physical distancing, are critical elements of this strategy (8). Persons should not travel if they are experiencing symptoms compatible with COVID-19 or if they have received a positive SARS-CoV-2 test result and have not met criteria to discontinue isolation, have had close contact with a person with suspected or confirmed COVID-19 and have not subsequently met criteria to end quarantine, ${ }^{* *}$ or have a pending SARS-CoV-2 viral test result.

\footnotetext{
I https://www.cdc.gov/coronavirus/2019-ncov/hcp/disposition-in-homepatients.html

** https:/www.cdc.gov/coronavirus/2019-ncov/more/scientific-brief-optionsto-reduce-quarantine.html
}

\section{Acknowledgments}

Geremy Lloyd, CDC COVID-19 Response Team; Tai-Ho Chen, Clive Brown, Araceli Rey, Division of Global Migration and Quarantine, National Center for Emerging and Zoonotic Infectious Diseases, CDC.

Corresponding author: Srikanth Ramachandruni, 8972ram@gmail.com.

\footnotetext{
${ }^{1}$ Corpus Christi-Nueces County Public Health District, Corpus Christi, Texas;

${ }^{2}$ Texas Department of State Health Services; ${ }^{3}$ CDC COVID-19 Response Team;

${ }^{4}$ Division of Global Migration and Quarantine, National Center for Emerging and Zoonotic Infectious Diseases, CDC.
}

All authors have completed and submitted the International Committee of Medical Journal Editors form for disclosure of potential conflicts of interest. No potential conflicts of interest were disclosed.

\section{References}

1. Public Health England. Investigation of novel SARS-CoV-2 variant: variant of concern 202012/01. Technical briefing 3. London, United Kingdom: Public Health England; 2020. https://assets.publishing. service.gov.uk/government/uploads/system/uploads/attachment_data/ file/950823/Variant_of_Concern_VOC_202012_01_Technical_ Briefing_3_-_England.pdf

2. Galloway SE, Paul P, MacCannell DR, et al. Emergence of SARS-CoV-2 B.1.1.7 lineage-United States, December 29, 2020-January 12, 2021. MMWR Morb Mortal Wkly Rep 2021;70:95-9. PMID:33476315 https://doi.org/10.15585/mmwr.mm7003e2

3. CDC, US Department of Health and Human Services. Requirement for negative pre-departure COVID-19 test result for all airline passengers arriving into the United States from the United Kingdom. Fed Regist 2020;85:86933-6. https://www.federalregister.gov/ documents/2020/12/31/2020-28981/requirement-for-negative-predeparture-covid-19-test-result-for-all-airline-passengers-arriving-into

4. CDC, US Department of Health and Human Services. Requirement for negative pre-departure COVID-19 test result or documentation of recovery from COVID-19 for all airline or other aircraft passengers arriving into the United States from any foreign country. Fed Regist 2021;86:7387-91. https://www.federalregister.gov/documents/2021/01/28/2021-01977/ requirement-for-negative-pre-departure-covid-19-test-result-ordocumentation-of-recovery-from

5. Pray IW, Ford L, Cole D, et al.; CDC COVID-19 Surge Laboratory Group. Performance of an antigen-based test for asymptomatic and symptomatic SARS-CoV-2 testing at two university campuses-Wisconsin, SeptemberOctober 2020. MMWR Morb Mortal Wkly Rep 2021;69:1642-7. PMID:33382679 https://doi.org/10.15585/mmwr.mm695152a3

6. Prince-Guerra JL, Almendares O, Nolen LD, et al. Evaluation of Abbott BinaxNOW rapid antigen test for SARS-CoV-2 infection at two community-based testing sites-Pima County, Arizona, November 3-17, 2020. MMWR Morb Mortal Wkly Rep 2021;70:100-5. PMID:33476316 https://doi.org/10.15585/mmwr.mm7003e3

7. Kucirka LM, Lauer SA, Laeyendecker O, Boon D, Lessler J. Variation in false-negative rate of reverse transcriptase polymerase chain reactionbased SARS-CoV-2 tests by time since exposure. Ann Intern Med 2020;173:262-7. PMID:32422057 https://doi.org/10.7326/M20-1495

8. Honein MA, Christie A, Rose DA, et al.; CDC COVID-19 Response Team. Summary of guidance for public health strategies to address high levels of community transmission of SARS-CoV-2 and related deaths, December 2020. MMWR Morb Mortal Wkly Rep 2020;69:1860-7. PMID:33301434 https://doi.org/10.15585/mmwr.mm6949e2 